\title{
Dano pelo sobrepeso de veículos comerciais ao pavimento flexível
}

\author{
Damage by overweight commercial vehicles to floor flexible
}

Thaís Ferrari Réus

thaisferrarireus@gmail.com

Universidade Estadual de

Londrina

\section{Carlos Alberto Prado da}

Silva Júnior

carlospradojr@hotmail.com

Universidade Estadual de

Londrina

Heliana Barbosa Fontenele heliana@uel.br

Universidade Estadual de

Londrina

\begin{abstract}
Resumo
O excesso de peso dos veículos comerciais é um dos principais problemas relativos à deterioração dos pavimentos. O objetivo deste trabalho foi verificar a adequação das cargas de tráfego à legislação, bem como quantificar o efeito de tal carregamento no pavimento. Para tanto, realizou-se simulações no programa ELSYM5 para a determinação das deformações do pavimento, empregadas no cálculo do Fator de Equivalência de Carga (FEC) empírico-mecanístico. Foram utilizados dados de pesagem do ano de 2009 de dois os postos localizados nas BR-153 e BR-369, situadas no norte do Paraná, bem como as cargas máximas permitidas por lei. Nos resultados, verificou-se um aumento de $5 \%$ a $40 \%$ nos FECs, em relação aos valores máximos. A partir dessa comparação, foi possível quantificar o efeito danoso proveniente do sobrepeso, em termos de equivalência ao do eixo padrão de 8,2 t, e perceber quanto o excesso de peso afeta o desempenho final do pavimento.
\end{abstract}

Palavras-chave: Excesso de carga, ELSYM5, pavimentos flexíveis.

\begin{abstract}
Overload of commercial vehicles is a major problem concerning the deterioration of pavements. The aim of this study was to verify the adequacy of traffic loads to legislation and quantify the effect of the loading on the pavement. To this end, were performed simulations in software ELSYM5, for determination of pavement deformation, used in calculation Load Equivalency Factor (FEC) mechanistic empirical. It was used weight data obtained in 2009 from two stations located in the BR-153 and BR-369, located in northern Paraná, and the maximum loads permitted by law. In the results, there was an increase of $5 \%$ to $40 \%$ in FECs with respect to maximum values. From this comparison, it was possible to quantify the harmful effect from the overload, in terms of equivalence to the standard axle of $8.2 \mathrm{t}$, and to realize how much the overload affects the final performance of the pavement.
\end{abstract}

Keywords: Overload, ELSYM5, flexible pavements.

\section{Introdução}

No Brasil, aproximadamente $60 \%$ do transporte de cargas é realizado pelo modal rodoviário, pois este apresenta maior flexibilidade, com veículos de tamanhos e capacidades diversificados, atingindo quase a totalidade do território nacional.

Segundo o relatório do Sistema de Gerenciamento de Pavimentos (SGP) do Departamento Nacional de Infraestrutura de Transportes, DNIT (2011), dos 1.712.517,3 km de rodovias brasileiras, apenas 214.413,5 km são pavimentados, ou seja, 12,5\%. Em uma avaliação qualitativa realizada em $96.714 \mathrm{~km}$ da malha de rodovias pavimentadas, 49,9\% foram classificadas em condições que variavam entre o estado regular e o péssimo (CNT, 2014). A malha pesquisada corresponde a, aproximadamente, $45 \%$ das rodovias nacionais pavimentadas. Esse fato torna-se preocupante, pois a qualidade do pavimento é fundamental para manter os níveis de desempenho da rodovia, podendo comprometer a segurança dos usuários, além de aumentar o tempo e o custo das viagens.

Um dos motivos para o mau estado em que se encontram as rodovias brasileiras é o excesso de peso dos veículos comerciais de carga. Esse efeito destrutivo do excesso de peso pode ser percebido no dimensionamento dos pavimentos 
por meio do Fator de Equivalência de Carga (FEC), que relaciona cada tipo de eixo ou conjunto de eixos ao eixo padrão, e é utilizado na determinação do número equivalente de operações do eixo padrão $(\mathrm{N})$, representando todo o tráfego de forma simplificada.

Devido ao excesso de carga, conforme Fernandes Júnior (1994), a evolução da deterioração dos pavimentos torna-se muito acentuada, comprometendo, em um curto período de tempo, o conforto e a segurança do tráfego e aumentando os custos de operação dos veículos.

A carga por eixo dos veículos é considerada no cálculo dos FEC, determinado por meios empíricos ou empíricomecanísticos. Os métodos empíricos utilizam correlações desenvolvidas pela American Association of State Highway and Transportation Officials (AASTHO) e United States Army Corps of Engineers (USACE), na década de 1960, e tem como base a utilização do California Bearing Ratio (CRB) como parâmetro de medida da capacidade de suporte do subleito e dos materiais constituintes da estrutura do pavimento. Já os empíricos mecanísticos relacionam o empirismo com ensaios experimentais de campo ou laboratório, levando em consideração as respostas estruturais do pavimento, sendo, assim, mais indicados para representar a situação em campo.

O FEC tem sido muito utilizado como medida de desempenho estrutural de pavimentos porque mede, comparativamente ao eixo padrão, os efeitos que os excessos de carga por eixo causam à estrutura do pavimento, como os estudos realizados por Fontenele, Zanuncio e Da Silva Júnior (2011), Fernandes Júnior (2007) e Albano (2005).

Sendo assim, o objetivo deste trabalho foi quantificar o dano do excesso de peso dos veículos comerciais no Lote 1 do Anel de Integração do Paraná, do ponto de vista empírico-mecanístico.

O presente trabalho encontra-se dividido em oito itens: o primeiro é a parte introdutória; o segundo trata da transmissão de cargas ao pavimento; o terceiro, dos conceitos de equivalência de carga; no quarto item, abordam-se os excessos de carga; no quinto, são descritos os mecanismos de deterioração do pavimento; no item seis, são detalhados os materiais e método da pesquisa; no sétimo, tem-se a apresentação dos resultados; e no oitavo, as conclusões.

\section{Transmissão de Carga ao Pavimento}

A carga por eixo, dividida entre o número de rodas, é transmitida por meio do contato dos pneus com o pavimento, sendo inicialmente absorvida pelo revestimento. Em seguida, a tensão se propaga e se espalha pelas camadas proporcionalmente à rigidez dos materiais empregados em sua constituição. Considerando-se que o pavimento é um meio elástico, isotrópico e homogênio, ocorre uma diminuição da força por área, ou seja, da tensão atuante, conforme apresentado na Figura 1.

Para tirar o máximo proveito desse tipo de propagação de tensões, as camadas são dispostas em ordem decrescente de capacidade de carga. Dessa forma, o material com maior resistência, e consequentemente mais caro, é utilizado para compor as faixas de rolamento na parte superior, e os que apresentam menor capacidade de suporte e menor custo são utilizados nas camadas inferiores (WAPA, 2013).

Figura 1: Transmissão de carga ao pavimento flexível

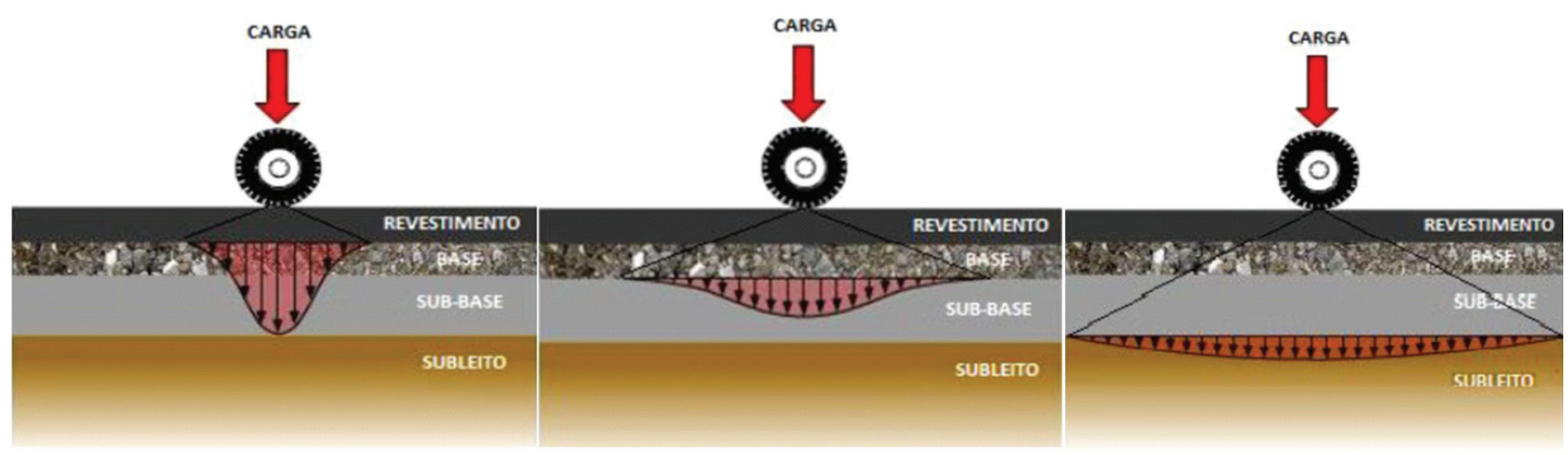

Fonte: Adaptado de WAPA, 2013 


\section{Equivalência de Cargas}

A observação do efeito causado por veículos diferentes em estruturas idênticas de pavimentos fez com que surgisse o conceito de equivalência de cargas. Os Fatores de Equivalência de Cargas (FEC) permitem a conversão de aplicações de diferentes solicitações em um número equivalente de solicitações do eixo padrão. Isso possibilita o dimensionamento e a previsão do desempenho de pavimentos para o tráfego, considerando toda a gama de veículos que o compõe.

O eixo padrão foi definido por estudos desenvolvidos pela AASHTO Road Test, no final dos anos 1950. Trata-se de um eixo simples, com rodado duplo e carga de $82 \mathrm{kN}(18.000 \mathrm{lb})$ e $563 \mathrm{kPa}(80$ psi) de pressão de inflação dos pneus.

\subsection{Fator de equivalência de carga empírico mecanístico}

Os modelos empírico-mecanísticos são baseados nas relações de causa e efeito, ou seja, por meio das solicitações se determinam as respostas estruturais do pavimento, e a partir disso procura-se entender os mecanismos de deterioração que são observados em campo.

Fernandes Júnior (1994) enfatizou que os FEC empírico-mecanísticos são os mais indicados para a previsão de desempenho, pois expressam melhor as situações em campo e podem ser obtidos por meio da Equação (1).

$$
F E C=\left(\frac{\rho_{i}}{\rho_{0}}\right)^{b}
$$

Em que:

- $\rho_{\mathrm{i}}=$ Resposta estrutural correspondente à solicitação em análise;

- $\rho_{0}=$ Resposta estrutural correspondente à solicitação padrão;

- $\mathrm{b}$ = Expoente associado à forma de deterioração, à resposta estrutural considerada, ao tipo de ensaio e à estrutura analisada;

De acordo com Fernandes Júnior et al. (2002), o expoente b é determinado a partir de correlações entre as análises mecanísticas e os resultados de observações do pavimento em serviço.

\section{Excessos de Carga}

A estrutura do pavimento, a segurança, o conforto e a fluidez do tráfego, entre outros fatores, são diretamente afetados pelos excessos de carga. Porém, estes continuam sendo praticados pela inexistência dos sistemas de pesagem na maioria das rodovias e das vantagens econômicas na relação entre o valor dos fretes e das multas aplicadas pela sobrecarga (Fontenele, Zanuncio e Da Silva Júnior, 2011). Além disso, os excessos de carga por eixo são vistos pelos transportadores como forma de aumentar a produtividade dos fretes; dessa forma, mesmo quando há fiscalização e autuação pelo sobrepeso, a relação frete/multa é economicamente vantajosa.

Segundo reportagem do portal de notícias G1 (2013), um levantamento realizado pela Controladoria Geral da União constatou um prejuízo de $\mathrm{R} \$ 1,6$ bilhão por ano com a recuperação de pavimentos, devido à degradação pelo excesso de peso dos veículos, praticados principalmente pela falta de fiscalização. Foi ressaltado também que, em 2012, o DNIT notificou 528 mil motoristas em rodovias federais por circularem com excedente de carga. Os excessos de carga podem trazer vários efeitos, como a redução da velocidade de tráfego, o comprometimento da segurança, o aumento do risco de acidentes e a redução da vida útil do pavimento.

Fontenele, Zanuncio e Da Silva Júnior (2011) verificaram em seu trabalho que o excesso de 1,0 t no peso por eixo simples, tandem duplo e tandem triplo, gera, respectivamente, um aumento de mais de $80 \%, 35 \%$ e $25 \%$ do FEC, ocasionando a degradação acelerada do pavimento e intervenções antes do tempo previsto em projeto.

Albano (2005) constatou, por meio da determinação do FEC empírico-mecanístico, com base nas deflexões calculadas no ELSYM5, que quando houve um excesso de $20 \%$ no peso do rodado duplo do simulador de tráfego utilizado, considerando o expoente $b=5,959$, ocorreu uma redução de $65,2 \%$ na vida útil prevista para o pavimento espesso e de $73,7 \%$ no pavimento delgado. Quando considerado o expoente $b=4,32$ para o cálculo do FEC, a redução foi de $53,4 \%$ para o pavimento espesso e de $62,0 \%$ para o delgado. 


\subsection{Limites legais no país}

Conforme determinado no Código de Trânsito Brasieliro (CTB), o Conselho Nacional de Trânsito (CONTRAN) é o órgão responsável por regulamentar o transporte rodoviário, por meio de resoluções. No que tange o transporte de carga, as Resoluções $n^{\circ} 210$ (CONTRAN, 2006) e a $n^{\circ} 211$ (CONTRAN, 2006b) estabelecem os limites de peso e dimensões para os veículos que transitem por vias terrestres e os requisitos necessários à circulação de Combinações de Veículos de Carga (CVC), respectivamente.

No que diz respeito ao Peso Bruto Total (PBT) e Peso Bruto Total Combinado (PBTC), a Lei no 7.408 , de 1985 (Brasil, 2013), estabeleceu uma tolerância percentual de 5\% atribuída ao limite máximo permitido, devido à imprecisão dos equipamentos de verificação de peso. Porém, quanto ao peso por eixo, admitiu-se uma alteração da tolerância de 5\% para 7,5\%, conforme Resolução $\mathrm{n}^{\circ}$ 102/99 (CONTRAN, 1999) e 104/99 do CONTRAN (1999b), revogadas pela Resolução $n^{\circ}$ 258, de 30 de novembro de 2007 (CONTRAN,2007). Na Resolução $n^{\circ}$ 258/07, a tolerância para os excessos de peso por eixo foi alterada para $5 \%$, porém, essa redução só foi efetivamente aplicada pela resolução 430/13 (CONTRAN, 2013), que passou a vigorar em 31 de dezembro de 2013.

Peterlini (2006) ressaltou em seu trabalho a necessidade da redução da tolerância de 7,5\%, uma vez que esta não leva em conta o caráter danoso aos pavimentos, além de que os transportadores consideram essa tolerância como um ganho real de sobrecarga, e não como uma tolerância do próprio equipamento de pesagem.

\section{Mecanismos de Deterioração do Pavimento}

Neste trabalho, são considerados apenas dois mecanismos de deterioração do pavimento: as trincas por fadiga e os afundamentos nas trilhas de rodas, por se tratarem dos principais defeitos oriundos da ação do tráfego.

Conforme abordado anteriormente, quando se tem a aplicação das cargas de tráfego no pavimento, considerando este como um meio elástico, isotrópico e homogêneo, há uma propagação de tensões com o aumento da profundidade e a consequente diminuição das solicitações. Esse carregamento aplicado ao pavimento gera deformações em sua estrutura, tratadas também como respostas estruturais, como a deformação horizontal de tração na fibra inferior do revestimento $\left(\varepsilon_{\mathrm{ht}, 1}\right)$ e deformação vertical de compressão no topo do subleito $\left(\varepsilon_{\mathrm{vc}, \mathrm{m}}\right)$, as quais foram consideradas neste trabalho.

\section{Materiais e Método}

Neste item, apresentam-se os materiais e métodos aplicados no desenvolvimento do trabalho. Os dados utilizados foram coletados nas pesagens diárias no ano de 2009, a partir de duas balanças localizadas na região norte do estado do Paraná, tendo como objetivo principal verificar o excesso de carga nas rodovias no lote 1 do anel de integração viário.

O trecho estudado conta com dois pontos de pesagem fixa (PPVs): um localizado na BR 369, km 10, no município de Cambará; e outro no km 5 da BR 153, no município de Jacarezinho. Os dois PPVs possuem balanças dinâmicas, que possibilitam realizar o controle de peso e dimensões de todos os veículos de transporte de cargas que trafegam pelo lugar, por $24 \mathrm{~h}$.

Os dados concedidos pela empresa concessionária foram os mesmos passados ao Departamento de Estradas e Rodagens (DER), fornecidos em forma de planilhas, sendo divididos entre os dois PPVs. Tais informações são as seguintes: quantidade de veículos pesados, dia a dia, mês a mês; os veículos autuados e o valor total em Unidade Fiscal de Referência (UFIR), divididos entre veículos com placas do Paraná e de outros estados; quantidade de veículos com excesso no Peso Bruto Total (PBT); e os valores médios dos excessos nos eixos em toneladas. Nas planilhas, percebeu-se que a forma de agrupamento das classes dos veículos feita pela empresa é a apresentada na Tabela 1.

Tabela 1: Classificação de veículos utilizada pela concessionária

\begin{tabular}{c|c|c}
\hline Classificação & Descrição & Número de Eixos \\
\hline Carreta & Caminhões tratores + Reboque/semirreboque & 4 a 6 \\
\hline Caminhões & Caminhões tratores & 2 a 3 \\
\hline Veículos especiais & Caminhões tratores + Reboque/semirreboque & mais de 7 \\
\hline Ônibus & Todos & - \\
\hline
\end{tabular}


Para cada carga por roda correspondente à média mensal dos pesos que excederam o limite de peso para o Eixo Simples de Rodas Duplas (ESRD), o Eixo Tandem Duplo (ETD) e o Eixo Tandem Triplo (ETT), foram calculadas as respostas do pavimento. Posteriormente, foi aplicada a Equação (1) para obtenção dos valores referentes aos FEC de cada tipo de eixo. O mesmo foi feito para as cargas máximas admissíveis por eixo (sem considerar a tolerância).

Para o cálculo dos correspondentes FECtrincas e FECafundamento pela Equação (1), foram considerados, respectivamente, a maior $\varepsilon h t, 1$, com o expoente 3,291, bem como a maior $\varepsilon v \mathrm{vc}, \mathrm{m}$, com o expoente igual a 4. Esses expoentes são os mesmos utilizados por Fontenele (2011) e estão relacionados ao tipo de estrutura analisada, à resposta estrutural e à forma de deterioração.

Para o cálculo das deformações $\left(\varepsilon_{\mathrm{ht}, 1}\right.$ e $\left.\varepsilon_{\mathrm{vc}, \mathrm{m}}\right)$ no programa ELSYM5, a estrutura hipotética do pavimento adotada foi a mesma utilizada por Fontenele (2011), e está apresentada na Tabela 2.

No processamento, considerou-se a distância entre centros das superfícies de carregamento no ESRD igual a $33 \mathrm{~cm}$; e nos ETD e ETT, a $120 \mathrm{~cm}$. Na Tabela 3, encontram-se as localizações das cargas e dos pontos de análise para cada tipo de eixo.

Tabela 2: Características do pavimento hipotético

\begin{tabular}{c|c|c|c}
\hline Camadas & Espessura $(\mathrm{cm})$ & Módulo de Elasticidade $(\mathrm{GPa})$ & Coef. Poisson \\
\hline \hline 1 & 12,70 & 41368,80 & 0,30 \\
\hline 2 & 20,32 & 4136,88 & 0,40 \\
\hline 3 & 25,40 & 2068,44 & 0,40 \\
\hline Subleito & $\infty$ & 689,48 & 0,45 \\
\hline
\end{tabular}

Tabela 3: Localizações usadas no ELSYM5 para cálculo das respostas estruturais

\begin{tabular}{c|c|c|c|c}
\hline \multirow{2}{*}{ Eixo } & \multicolumn{2}{|c}{ Localização das Cargas (cm) } & \multicolumn{2}{c}{ Localização de Análise (cm) } \\
& $\mathrm{x}$ & $\mathrm{y}$ & $\mathrm{x}$ & $\mathrm{y}$ \\
\hline \hline \multirow{2}{*}{ ESRD } & 0 & 0 & 16,66 & 0 \\
& 33,30 & 0 & 0 & 0 \\
\hline \multirow{5}{*}{ ETD } & 0 & 0 & 16,66 & 0 \\
& 33,30 & 119,99 & 0 & 60,96 \\
& 0 & 119,99 & 16,66 & 60,96 \\
\hline \multirow{5}{*}{ ETT } & 33,30 & 0 & 0 & 0 \\
& 0 & 0 & 16,66 & 0 \\
& 33,30 & 119,99 & 0 & 60,96 \\
& 0 & 119,99 & 16,66 & 60,96 \\
& 33,30 & 239,98 & 0 & 119,99 \\
& 0 & 239,98 & 16,66 & 119,99 \\
\hline
\end{tabular}

De acordo com Fernandes Júnior et al. (2007), a pressão de enchimento média utilizada no Brasil é de 844 kPa (120 psi), que foi adotada para a determinação das respostas estruturais deste trabalho. A única exceção foi para a obtenção das deformações referentes às solicitações do eixo padrão, para o qual a pressão de enchimento foi a convencionalmente adotada, de $563 \mathrm{kPa}(80 \mathrm{psi})$. 


\section{Resultados}

\subsection{Configuração do tráfego circulante}

No PPV da BR-153, em 2009, houve uma operação regular ao longo do ano, porém, pode-se perceber que, no primeiro semestre, o volume de veículos pesados foi de 768 veículos por mês, significativamente menor que o do segundo semestre, que atingiu 1.178 veículos fiscalizados por mês.

Pode-se notar que caminhões aparecem com maior frequencia, representando em média $40 \%$ dos veículos fiscalizados, mas praticamente empatados com as carretas, que tiveram em média 38\%. Os veículos especiais aparecem com $19 \%$; e os ônibus, com cerca de $2 \%$ de representatividade.

No PPV da BR-369, no ano de 2009, perceberam-se dois períodos distintos: um representado pelo primeiro semestre, quando houve um volume significativamente baixo de pesagem, com média de 302 veículos por mês; e o segundo semestre, quando se teve um fluxo de operação maior, cuja média foi de 2.979 veículos por mês. Esse fato foi decorrente da manutenção das balanças realizada no primeiro semestre, o que impossibilitou a operação em alguns meses ou fez com que houvesse a operação parcial do posto de pesagem nos outros.

Com relação às configurações do tráfego, pode-se notar, em média, $46 \%$ de frequencia de caminhões, $39 \%$ de carretas, $15 \%$ de ônibus e $1 \%$ de veículos especiais.

\subsection{Excessos de carga}

O maior número de excessos no PBT ocorreu nos meses de setembro a dezembro, época de safra na região. Em média, 16\% das carretas apresentaram sobrepeso, 12\% dos caminhões e dos ônibus, e $11 \%$ dos veículos especiais. Também é possível verificar que o valor mais expressivo para os excessos de carga é referente aos ônibus no mês de outubro, quando $70 \%$ dos veículos fiscalizados trafegavam acima do limite de carga permitido.

Na BR-369, os caminhões foram os que apresentaram maior incidência de sobrepeso. Os excessos de peso foram constados com mais frequência entre os meses de julho e setembro. Em média, 14\% dos veículos especiais apresentaram sobrepeso, $11 \%$ dos caminhões, $10 \%$ das carretas e dos ônibus.

Os excessos de carga por eixo, constatados no PPV da BR-153, variaram de $1.180 \mathrm{~kg}$ a $4.045 \mathrm{~kg}$, sendo que o menor foi verificado para o eixo simples de rodas duplas, e o maior para o eixo tandem triplo. Na Figura 2, pode-se visualizar que a distribuição dos excessos de carga ao longo dos meses é praticamente regular para os ESRD e ETD.

Os excessos de peso registrados no PPV da BR-369 variaram de $350 \mathrm{~kg}$ a $4.350 \mathrm{~kg}$. O menor excesso verificado foi para o ESRD, e o maior para o ETD. A distribuição dos excessos de carga não se deu uniformemente ao longo do ano, como pode ser percebido na Figura 3, e o maior número de excessos foi constatado no período em que houve a operação plena do PPV, mesmo período em que as pesagens foram realizadas apenas em caráter estatístico.

Figura 2: Porcentagem excesso de carga por tipo de eixo no PPV da BR-153 em 2009

PPV BR-153

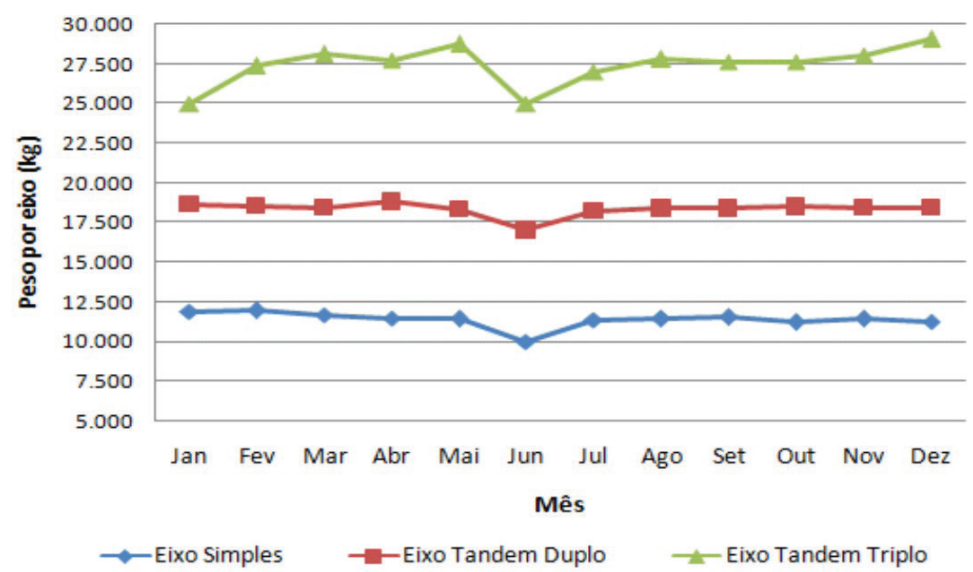


Figura 3: Porcentagem excesso de carga por tipo de eixo no PPV da BR-369 em 2009

PPV BR-369

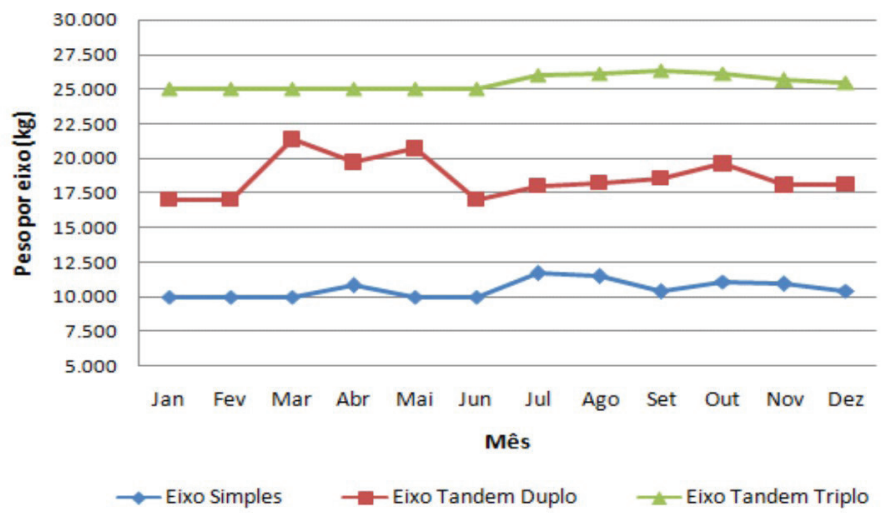

\subsection{FEC empírico-mecanístico}

Com base nos resultados das análises estruturais do ELSYM5, calcularam-se os FEC empírico-mecanísticos. Para a averiguação dos efeitos danosos dos excessos de carga para o pavimento, determinaram-se os FEC para os limites máximos de carga permitidos pela legislação brasileira para cada tipo de eixo, sendo estes apresentados na Tabela 4.

Tabela 4: FEC empírico-mecanístico máximos por eixo

\begin{tabular}{|c|c|c|c|}
\hline FECmáx. & ESRD & ETD & ETT \\
\hline FECtrincas & 2,42 & 1,52 & 1,51 \\
\hline FECafund. & 3,00 & 1,88 & 1,87 \\
\hline
\end{tabular}

Foi verificado que os FECafundamento apresentaram-se mais danosos que os de FECtrinca em cerca de 25\%, bem como a evolução do efeito danoso de acordo com o aumento da carga por eixo. Nas Figuras 4, 5 e 6, verifica-se a distribuição dos FEC calculados ao longo dos meses.

Figura 4: Valores de FEC por tipo de eixo em 2009

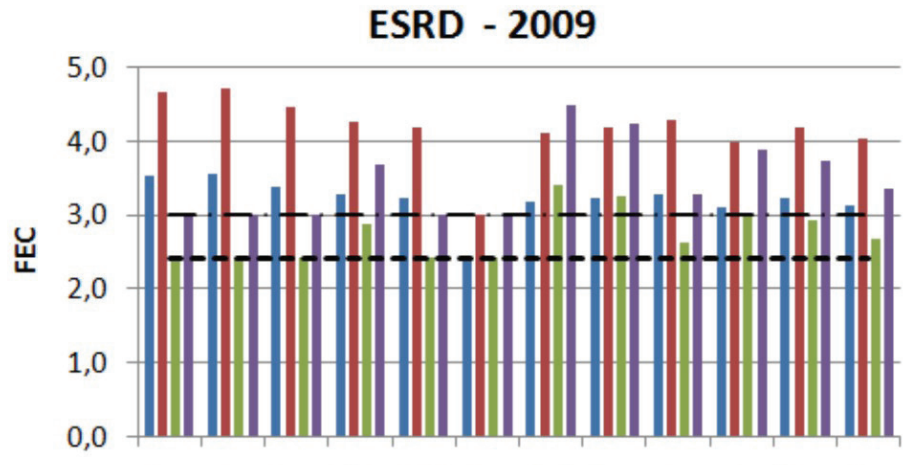

Jan Fev Mar Abr Mai Jun Jul Ago Set Out Nov Dez

Meses 
Figura 5: Valores de FEC por tipo de eixo em 2009

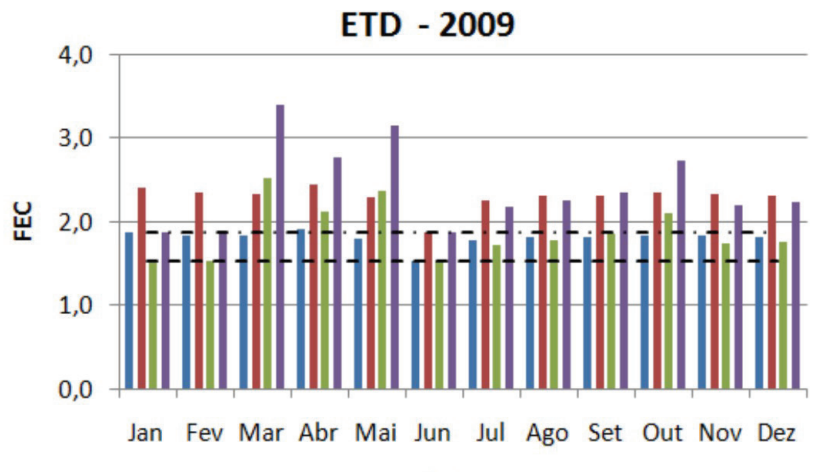

Meses

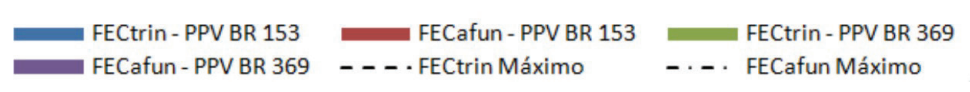

Figura 6: Valores de FEC por tipo de eixo em 2009

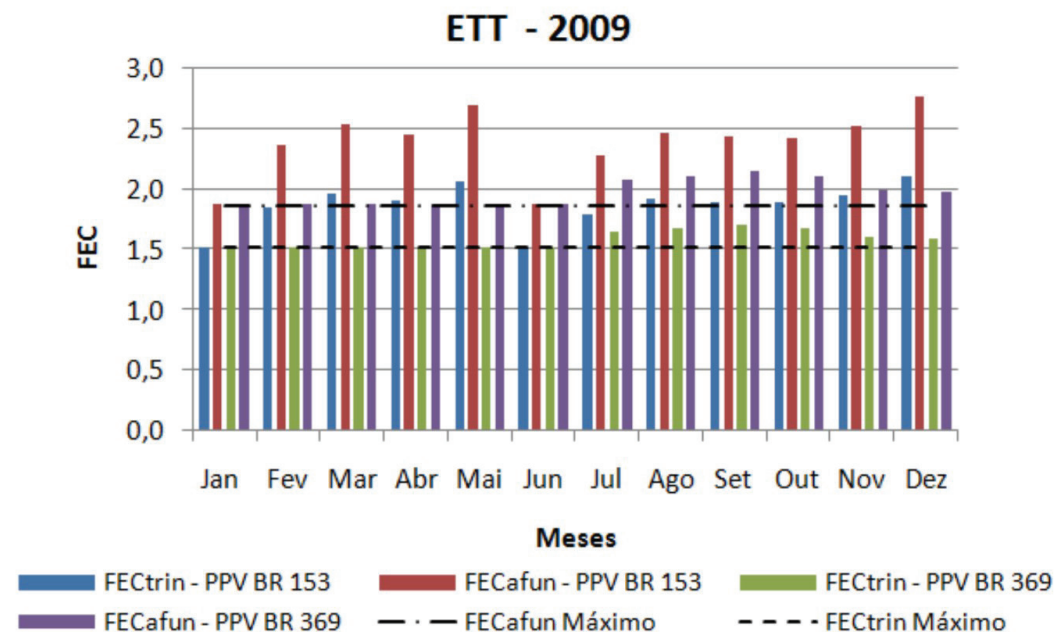

Nas Figuras 4 a 9, observa-se que, no PPV da BR-153, os FEC obtidos para o carregamento real foram cerca de $40 \%$ maiores que os FECmáx relativos às trincas e afundamentos para o ESRD e 25\% para o ETD. No ETT, verificou-se que, para trincas, os FEC apresentaram-se aproximadamente $25 \%$ acima do máximo; e para o afundamento, cerca de $30 \%$. No posto de pesagem da BR-369, no primeiro semestre, os FEC foram calculados em função da carga limite, pois não houve operação da balança. No segundo, foi possível observar FEC de trinca e de afundamento cerca de $20 \%$ maiores que os máximos para o ESRD, e de 5\% para o ETT. Quanto ao ETD, verificou-se FEC cerca de 30\% maiores para trincas e de $40 \%$ para o afundamento nas trilhas de roda.

Pelos gráficos, também se pode perceber que houve uma redução do dano causado ao pavimento, em relação às solicitações do eixo padrão, do ESRD para o ETD, e também do ETD para o ETT, fato que pode ser explicado pela melhor distribuição da carga ao pavimento. 
Figura 7: Aumento do FEC em relação ao FEC máximo em 2009

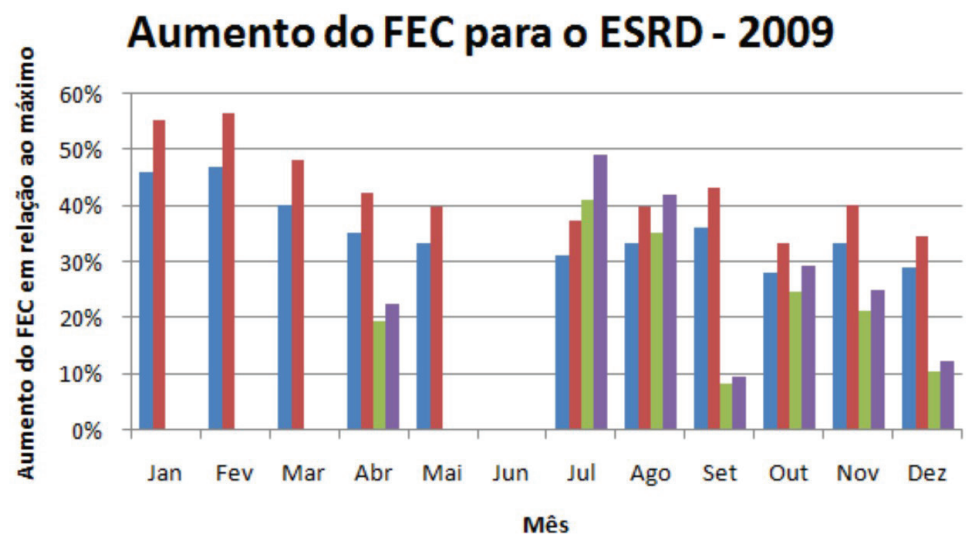

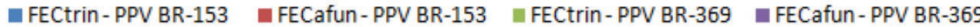

Figura 8: Aumento do FEC em relação ao FECmáximo em 2009

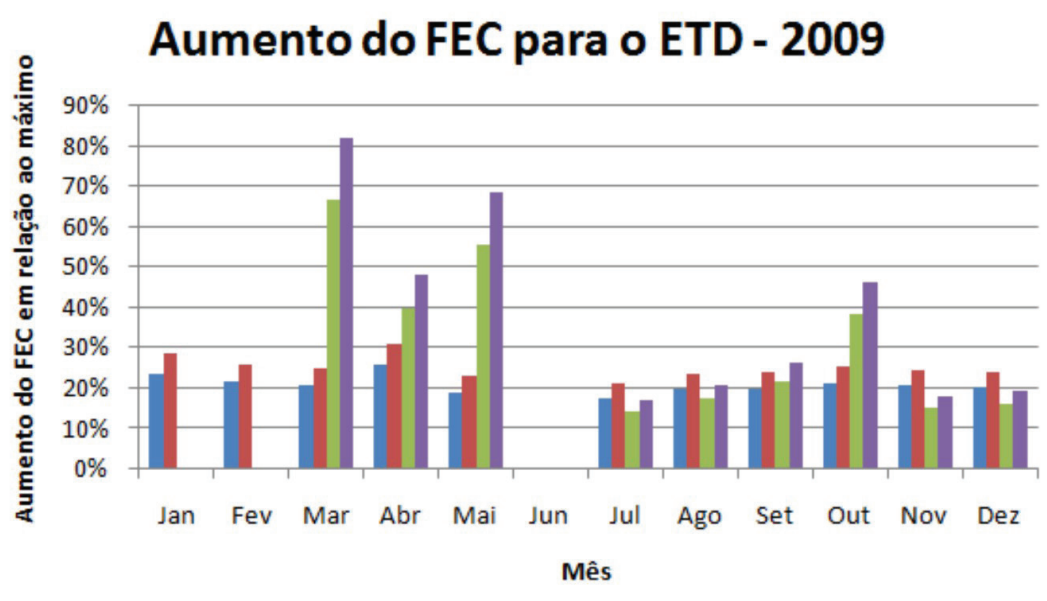

- FECtrin - PPV BR-153 = FECafun-PPV BR-153 = FECtrin - PPV BR-369 = FECafun-PPV BR-369

Figura 9: Aumento do FEC em relação ao FECmáximo em 2009

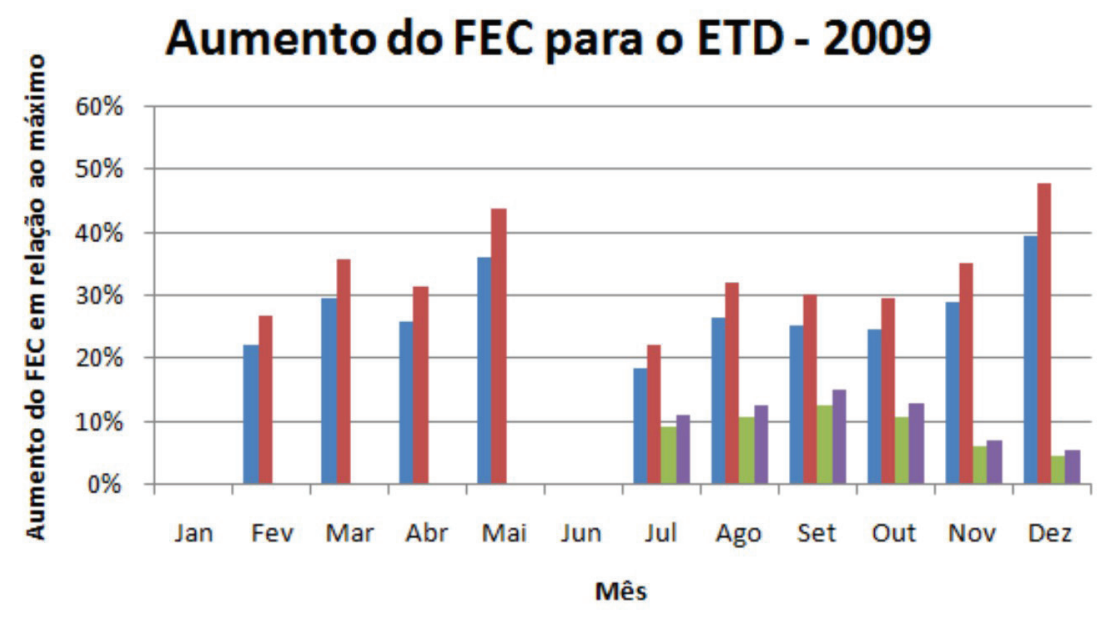

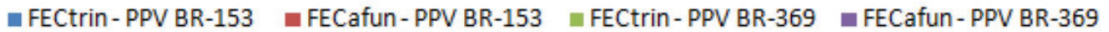




\section{Conclusões}

Foi possível perceber que a circulação de caminhões e carretas é predominante no lote 1 do Anel de Integração do Paraná. Mas as carretas são mais frequentes no primeiro semestre, e os caminhões no segundo, em ambos os PPVs.

Os resultados obtidos mostraram a necessidade de uma fiscalização mais rigorosa, uma vez que o tráfego com carga excedente é corriqueiro. Quanto aos excessos de carga no PBT, constatou-se que os caminhões apresentam maior média de sobrepeso durante o ano. Além disso, também se percebeu a importância da fiscalização dos ônibus, uma vez que cerca de $70 \%$ circulavam com carga acima do limite permitido.

Tratando-se dos excessos de carga por eixo, constatou-se que, para o PPV da BR-153, os maiores ocorreram para o ETT, enquanto na BR-369 ocorreram para o ETD.

Os valores de FEC encontrados demonstram o quão prejudicial é o excesso de peso para a vida útil do pavimento, sendo que, com os dados utilizados no estudo, o aumento do FEC chegou a 80\% em relação ao máximo, calculado com o limite de carga permitido pela legislação sem considerar a tolerância.

Outro fato importante foi que o FEC referente ao afundamento nas trilhas de roda apresentou-se $25 \%$ maior que o referente às trincas por fadiga, explicando, assim, uma das principais deteriorações encontradas nas rodovias da região.

Esses resultados mostram a grande necessidade de um estudo sobre a forma que está sendo feita a fiscalização no Brasil. Atualmente, não há nenhuma intensificação das operações nos meses críticos do ano na região em estudo, de setembro a dezembro, meses nos quais se tem o escoamento da safra de grãos.

Através da análise dos resultados encontrados, conclui-se que o cenário do carregamento das vias é preocupante, pois os excessos de carga praticados pelos transportadores são muito frequentes, não havendo consciência por parte destes quanto aos danos causados ao pavimento. Esse fato leva à necessidade de intervenção para a recuperação do pavimento em tempos cada vez menores. Sendo assim, a fiscalização deve ser intensificada e a autuação dos veículos precisa ser realizada com frequencia, para que o excesso de carga seja inibido.

\section{Agradecimentos}

Ao CNPq pela bolsa de estudos concedida e à Fundação Araucária e ao CNPq pelo apoio ao projeto (Chamada 14/2011, pesquisa de Protocolo n 24685).

\section{Referências}

ALBANO, J. F. Efeitos dos excessos de carga sobre a durabilidade dos pavimentos. 2005. $232 \mathrm{f}$. Tese (Doutorado em Engenharia de Produção) - Programa de Pós-Graduação em Engenharia de Produção, Universidade Federal do Rio Grande do Sul, Porto Alegre, 2005.

BRASIL. Lei n. ${ }^{\circ}$ 7.408, de 25 de novembro de 1985. Permite a tolerância de 5\% (cinco por cento) na pesagem de carga em veículos de transporte. Diário Oficial [da] República Federativa do Brasil, Brasília, DF, 25 nov. 1985. Disponível em: <http://www.planalto.gov.br/ccivil_03/leis/L7408.htm >. Acesso em: 01 maio 2013.

CONSELHO NACIONAL DE TRÂNSITO. Resolução no 102/99 de 20/09/1999. Dispõe sobre a tolerância máxima de 7,5\% sobre o peso bruto transmitido por eixo de veículos das vias públicas. Brasília, 1999a. 1p. Disponível em: <http:// www.denatran.gov.br/resolucoes.htm>. Acesso em: 2 jun. 2013.

CONSELHO NACIONAL DE TRÂNSITO. Resolução $n^{\circ}$ 104/99 de 21/12/1999. Dispõe sobre a tolerância máxima de peso bruto de veículos e estabelece critérios para aplicação de multas. Brasília, 1999b. 2p. Disponível em: <http://www. denatran.gov.br/resolucoes.htm>. Acesso em: 2 jun. 2013.

CONSELHO NACIONAL DE TRÂNSITO. Resolução $n^{\circ}$ 210/06 de 13/11/2006. Estabelece os limites de peso e dimensões para veículos que transitem por vias terrestres e dá outras providências. Brasília, 2006. 7p. Disponível em: $<$ http://www.denatran.gov.br/resolucoes.htm>. Acesso em: 2 jun. 2013.

CONSELHO NACIONAL DE TRÂNSITO. Resolução no 211/06 de 13/11/2006. Requisitos necessários à circulaçao de Combinações de Veículos de Carga - CVC, a que se referem aos arts. 97, 99 e 314 do Código de Trânsito Brasileiro. Brasília, 2006b. 7p. Disponível em: <http://www.denatran.gov.br/resolucoes.htm>. Acesso em: 2 jun. 2013. 
do Código Trânsito Brasileiro, fixa metodologia de aferição de peso de veículos, estabelece percentuais de tolerância e dá outras providências. Brasília, 2007b. 5p. Disponível em: <http://www.denatran.gov.br/resolucoes.htm>. Acesso em: 2 jun. 2013.

CONSELHO NACIONAL DE TRÂNSITO. Resolução $n^{\circ}$ 430/13 de 29/01/2013. Altera o prazo previsto no artigo 17 da Resolução CONTRAN nº 258/2007, com redação dada pelas Resoluções nº 365/2010 e 403/2012, que regulamenta os artigos 231, X e 323 do Código de Trânsito Brasileiro, fixa metodologia de aferição de peso de veículos, estabelece percentuais de tolerância e dá outras providências. Brasília, 2013. 2p. Disponível em: <http://www.denatran.gov.br/ resolucoes.htm>. Acesso em: 2 jun. 2013.

CONFEDERAÇÃO NACIONAL DO TRANSPORTE. Relatório pesquisa CNT de rodovias 2014. Brasília, 2014.

DEPARTAMENTO NACIONAL DE INFRAESTUTURA DE TRANSPORTE. Diretoria de Planejamento e Pesquisa. Relatório dos levantamentos funcionais das rodovias federais. Rio de Janeiro, 2011.

EXCESSO de peso de caminhões causa prejuízo de R \$1,6 bilhão em estradas. G1 - Portal de notícias, Rio de Janeiro, 22 abr. 2013. Disponível em: <http://g1.globo.com/bom-dia-brasil/noticia/2013/04/excesso-de-peso-de-caminhoescausa-prejuizo-de-r-16-bilhao-em-estradas.html>. Acesso em: 5 jun. 2013.

FERNANDES JUNIOR, J. L. Investigação dos Efeitos das Solicitações do Tráfego sobre o Desempenho de Pavimentos. 1995. 293 f. Tese (Doutorado em Engenharia Civil) - Pós-graduação em Engenharia Civil, Escola de Engenharia de São Carlos, Universidade de São Paulo, São Carlos, 1995.

FERNANDES JÚNIOR, J. L. et al. Efeitos dos pneus trelleborg sobre pavimentos asfálticos. Minerva, São Carlos - SP, v. 2, n. 1, p. 13-24, jan-jun 2002.

FERNANDES JUNIOR, J. L.; PAES, J. C.; PEREIRA, P. A. A. Avaliação dos efeitos das solicitações do tráfego sobre o desempenho de pavimentos flexíveis portugueses e brasileiros. Revista Pavimentação, Rio de Janeiro, ano 2, n. 5, p. 28-38, mar. 2007.

FONTENELE, H. B.; ZANUNCIO, C. E. M.; SILVA JUNIOR, C. A. P. da. O excesso de peso nos veículos rodoviários de carga e seu efeito. Teoria e Prática na Engenharia Civil, Rio Grande, v. 11, n. 18, p. 95-103, nov. 2011.

FONTENELE, H. B. Representação do tráfego de veículos rodoviários de carga através de espectros de carga por eixo e seu efeito no desempenho dos pavimentos. 2011. 287 p. Tese (Doutorado em Engenharia) - Escola de Engenharia de São Carlos, Universidade de São Paulo, São Carlos, 2011.

PETERLINI, P. S. Cargas por eixo e fatores de veículos obtidos em rodovias federais concessionadas do Estado do Paraná. 2006. 210 f. Dissertação (Mestrado em Engenharia Civil) - Programa de Pós-Graduação em Engenharia Civil da Universidade Federal de Santa Catarina, Florianópolis, SC, 2006.

WASHINGTON ASPHALT PAVEMENT ASSOCIATION. Asphalt Pavement Guide. Disponível em: < http://www. asphaltwa.com>. Acesso em: 5 jun. 2013.

Sobre os autores

\section{Thais Ferrari Réus}

Engenheira Civil, Universidade Estadual de Londrina - UEL. Mestranda do Programa de Pós-Graduação em Engenharia de Edificações e Saneamento, área de Engenharia de Edificações e Saneamento, UEL.

\section{Carlos Alberto Prado da Silva Júnior}

Engenheiro Civil. Doutor em Ciências - Área de planejamento de transportes pela Escola de Engenharia de São Carlos- USP. Professor Adjunto da Universidade Estadual de Londrina - UEL.

\section{Heliana Barbosa Fontenele}

Engenheira Civil. Doutora em Ciências - Área de infraestrutura de transportes pela Escola de Engenharia de São Carlos- USP. Professora Adjunta da Universidade Estadual de Londrina - UEL. 